\title{
ESTUDO DA UTILIZAÇÃO DE ORGANIZAÇÕES SOCIAIS NO PODER PÚBLICO MUNICIPAL - A GESTÃO DOS CENTROS COMUNITÁRIOS NO MUNICÍPIO DE BARUERI-SP
}

\section{Prof. Msc. Vinícius Silveira de Almeida - FAC São Roque} vinicius.net@uol.com.br

\section{Prof. Dr. Marcelo Eloy Fernandes - Fatec Barueri / Universidade Paulista - UNIP / Uninove} marceloeloyfernandes@gmail.com

\section{Prof. Dr. Marcelo T. Okano}

Marcelo.okano@cps.sp.gov.br

Professor do Mestrado Profissional em Gestão e Tecnologia em Sistemas Produtivos

Doutor em Engenharia de Produção

Doutorando em Administração na FGV/EAESP

\section{Resumo}

As organizações sociais desempenham um papel relevante na gestão pública, onde realizam as funções que via de regra deveriam ser executadas pelo Estado, mas dado sua flexibilidade e ordenamento jurídico estas podem celebrar contratos diretos com o poder público para atendimento de uma função específica e não exclusiva. Normalmente estas O.S. (organizações sociais) atendem prioridades na área da saúde, que são os casos mais comuns de sua utilização e descentralização de funções. O município de Barueri traz uma nova ótica à utilização destas: a gestão de centros comunitários. O projeto que existiu no município durante os anos de 2013 e 2014 foi um dos maiores projetos sociais da história deste, que incluiu milhares de crianças e jovens e teve o maior orçamento já previsto nos registros contábeis para a realização de tal atividade. Partindo dessa premissa e analisando a realidade municipal, a necessidade de atendimento de crianças e jovens ainda existe, mas a organização social inicialmente responsável por administrar as ações já não se encontra mais a frente do projeto. 
Estudos e análises exploratórias permitem aferir em que nível o projeto impactou a sociedade civil, seus benefícios, o que ensejou sua descontinuidade, verificar se o poder público interferiu ou não na gestão e operacionalização das ações e se 0 propósito da gestão foi atingido no período. Assim, pretende-se entender o fenômeno da utilização de organizações sociais na gestão pública municipal na cidade de Barueri e entender o processo, as causas e as consequências de este não mais vigorar no município.

Palavras-chaves: Organização Social; Eficiência do Projeto; Interferências Políticas; Impacto Social; Disfunções Administrativas.

\section{Introdução}

As organizações sociais, comumente chamadas de O.S., são utilizadas como uma modalidade de prestação de serviços públicos por meio de parceria entre o Poder Público e organizações não-estatais no ordenamento das cidades e estados do nosso país. Foram formuladas no período do primeiro mandato do presidente Fernando Henrique Cardoso (1995-1999) e sua proposta foi concebida pelo então ministro Luiz Carlos Bresser Pereira e equipe, quando à frente do MARE - Ministério da Administração Federal e Reforma do Estado, através do marco legal na Medida Provisória n. 1591-1 de 6 de novembro de 1997 e reeditada até a conversão da lei n. 9637 de 15 de maio de 1998 (Schmidt, 2011). No que tange a esta lei, em seu primeiro artigo esta já menciona que "o Poder Executivo poderá qualificar como organizações sociais pessoas jurídicas de direito privado, sem fins lucrativos, cujas atividades sejam dirigidas ao ensino, à pesquisa científica, ao desenvolvimento tecnológico, à proteção e preservação do meio ambiente, à cultura e à saúde, atendidos aos requisitos previstos nesta Lei" o que enseja a possibilidade de atuação da entidade em áreas distintas da sociedade, de acordo com a elaboração de sua atividade fim (estatuto) e o seguimento das prerrogativas legais estabelecidas na própria lei (Art. $2^{\circ}$ ) para se qualificarem como aptas a celebrarem este tipo de relação com o Poder Público.

De acordo com Modesto (1997) "nenhuma entidade é constituída como organização social... é uma qualidade adquirida, resultado de um ato formal de reconhecimento do Poder Público, facultativo e eventual...". Tendo em vista a 
arbitrariedade do poder Executivo mediante a cessão de título de organização social às instituições de direito privado, concedendo a estas a administração direta ou indireta de atividades de relevância coletiva que possam ser cometidas a unidades sociais já existentes, como hospitais, museus, universidades e demais serviços de caráter público, de acordo com Moreira Neto (2014), Schimidt (2011) e Modesto (1997) houveram discussões e opiniões políticas contrárias que polarizaram os debates e gerou-se entrave por parte de grupos oposicionistas a este modelo de gestão. A base governista de FHC, no período, argumentava em favor da proposta por entender que o aumento do papel regulatório do Estado em detrimento da prestação direta de serviços seria a solução para as disfunções administrativas observadas no funcionamento dos serviços sociais. Grupos contrários, em especial as instituições relacionadas a área da Saúde (associações de classe e sindicatos) e alguns partidos políticos manifestaramse contra o modelo, pois, de acordo com Almeida (2012, p. 52) "a cultura institucionalizada é mantida porque também protege interesses concretos e orienta a distribuição de recursos e posições de poder no sistema". Qualquer forma de trabalho que modificasse o sistema de trabalho que prevalecia no período poderia, de forma direta, encontrar resistência dentro do próprio sistema institucional. Por esse mesmo motivo, muitos juristas na época colocaram em dúvida o modelo de O.S. proposto, por duas questões que consideravam fundamentais: a primeira era a sobre a natureza jurídica das organizações sociais e se as atividades desenvolvidas seriam atividades de serviços públicos ou de atividades privadas e a segunda questão é se haveria ou não a necessidade de realizar suas compras e contratações através de regime licitatório, assim como ocorrem com os entes da administração direta e indireta.

Desta forma, Modesto (1997) menciona que:

“ Não há, portanto, impedimento constitucional algum à assunção por particulares de tarefas e missões de interesse social em colaboração com a administração pública. Desde que cumpridos requisitos de salva-guarda do interesse público, mais intensos e onerosos quanto mais ampla for a transparência de encargos e recursos, a 
cooperação é lícita e até mesmo estimulada pela Constituição da República"

Apesar de diversas correntes de pensamentos concernentes à época discordarem por um conjunto de questões do modelo proposto para a efetivação dos serviços públicos, seja desde o enquadramento ou dúvida quanto a natureza jurídica, seja pelo debate político ou simplesmente por defesas de interesses não tão claros no que tange a entrega final do serviço ao público por órgãos ou classes de trabalhadores, as organizações sociais são uma realidade nas cidades e estados brasileiros e estão cada vez mais ativas e com maior parceria com o poder público, em especial o poder público municipal.

O artigo estruturar-se-á da seguinte forma: em sua primeira parte irá mostrar em qual período na gestão pública em que ensejou a criação das organizações sociais e os conflitos que advieram dessa proposta em nível federal. Logo após irá avaliar o momento político administrativo na época para se conceber a utilização da O.S. Inovação Social, em especial na área de infância, juventude e lazer em um município da grande São Paulo (Barueri). A seguir será feita a análise do programa inicial, da proposta e os relatórios de atividades para se entender quando se deu o ápice e a desagregação dos objetivos inicialmente propostos para o município e determinar se houve interferência política ou não e se, caso positivo, se isso impactou administrativamente o projeto social. Após isso, na próxima seção tentará levantar os benefícios ou prejuízos imputados à sociedade barueriense e concluirá com uma análise crítica dos motivos que imputaram com a descontinuidade da utilização desta organização social na área em que atuava.

\section{Da Metodologia de Pesquisa e da Análise dos Dados}

Para a realização deste estudo de caso foram analisados os dados quantitativos de todos os materiais impressos, relatórios de prestação de contas, descritivos de atividades cadastrados no sistema da Promoção Social do município de Barueri, bem como as prestações de contas e demais informes publicados em Diário Oficial municipal nos anos de 2013 e 2014. A análise organizacional, por incluir elementos que também expressavam a realidade do período e interação de diversos atores para resolver sua problemática do cotidiano, também utilizou de entrevistas com três 
colaboradores distintos que estavam no projeto deste seu início, cada um em um nível diferente da organização: operacional, técnico e estratégico. As informações qualitativas obtidas através dos relatos foram relacionadas através de perguntas não estruturadas e de resposta livre, deixando cada entrevistado explanar livremente. Desta maneira, buscou-se entender, de acordo com a metodologia proposta por Michel Crozier (1981) e conforme menciona Almeida (2015, p.17) os seguintes tipos de raciocínio:

“I) A lógica indutiva: da qual se busca entender a maneira de agir e de raciocinar do indivíduo dentro da estrutura formal (hierárquica) a qual pertence partindo para as premissas mais gerais da própria organização;

II) A lógica dedutiva: a cultura da organização, sua política, seus ambientes de ação e jogos estruturados, para que se chegue nas premissas mais específicas."

\section{Cenário do Município de Barueri no Período}

Após as eleições municipais de outubro 2012, uma nova gestão no município de Barueri se instituiu, sendo um grupo diferente (opositor) que alcançou o Poder Executivo, rompendo um ciclo de 8 anos da mesma gestão (ex-prefeito) e atingindo, também, a maioria das cadeiras legislativas (11 dos 21 vereadores) no período referido. Nas gestões anteriores ao período de 2012, os contratos celebrados para serviços de saúde no município de Barueri eram, quase que exclusivamente, utilizadas em objetos (equipamentos e próprios públicos) da área da Saúde, a saber: UBS (Unidades Básicas de Saúde), exames diversos e no hospital municipal. O município possui dentre os seus equipamentos de Saúde 16 UBS's, 1 Hospital Municipal e 5 Pronto-Socorros. Desses últimos, somente 2 (Pronto Socorro Central, compreendido o Pronto Socorro Infantil e o Pronto Socorro Adulto que se encontram limítrofes um ao outro) são gerenciados exclusivamente pela Secretaria de Saúde do município de Barueri. Na época havia um contrato de gestão que há muito vigorava, utilizando a expertise e o corpo técnico de médicos da UNIFESP, a organização social FPDM 
(Associação Paulista para o Desenvolvimento da Medicina) que administrava o único Hospital Municipal de Barueri (Hospital Dr. Francisco Mouran), hospital esse que foi inaugurado em 2008. Existe também a modalidade de terceirização, onde uma empresa que participou de uma licitação administra, concomitantemente, o Pronto Socorro do Jardim Mutinga e também o Pronto Socorro do Parque dos Camargos. Esta empresa é conhecida por UDI (Unidade de Diagnóstico Integrado) e desde meados dos anos 2000 toma conta desses próprios públicos. O Pronto Socorro do bairro chamado Engenho Novo era administrado também pela SDPM e hoje conta com a administração da organização social Pró-Saúde - Associação Beneficente de Assistência Social e Hospitalar. Recentemente houve uma ruptura no contrato de gestão do hospital municipal de Barueri e uma nova organização social, o Instituto Hygia de Saúde e Desenvolvimento Social começou a gerenciá-lo desde o dia 01/09/2014.

Existe, então, no município a facilitação da prestação de serviço público através da modalidade de contratação de organizações sociais para execução de serviços não exclusivos do poder público. Essa já é uma prática recorrente, que ultrapassa os períodos eleitorais (ciclos de 4 anos), e que com os dados disponíveis pode-se informar que há mais de uma década as organizações sociais contribuem de forma direta ou indireta na rotina da administração pública municipal de Barueri.

No início do ano de 2013 e até meados do ano de 2014 houve um projeto que foi capitaneado pela Secretaria de Mulher do município que foi intitulado "Centros Comunitários de Barueri", dos quais se dividiam em quatro unidades nos bairros periféricos da cidade (Parque dos Camargos, Engenho Novo, Jardim Paraíso e Parque Imperial). Estes disponibilizavam atividades "socioeducativas que garantam à proteção integral, a sociabilidade, a empregabilidade, o fortalecimento dos vínculos afetivos, a participação do núcleo familiar, o protagonismo juvenil e o engajamento com a comunidade local' (Relatório Semestral Projeto Integrando Famílias - julho a dezembro de 2013, pág 2), ou seja, ações lúdicas e programas que desenvolvam competências para o público que utilizava esses espaços, incluindo neste público crianças, adolescentes e até mesmo o público adulto.

Há uma disfunção burocrática em um projeto com esse escopo e abrangência ao estar relacionado com a Secretaria da Mulher do município, pois em sua descrição (resumo) do projeto as ações teriam maior aderência a outras Secretarias do município, de acordo com sua descrição e vocação dentro da cidade e paridade de 
projetos/programas que contenham similaridades: proteção integral (atividades relacionadas à Sec. de Promoção Social), sociabilidade (Sec. de Cultura e Sec. de Esportes), empregabilidade (Sec. de Desenvolvimento Econômico e Trabalho) e protagonismo juvenil (Sec. de Governo - Coordenadoria da Juventude e Políticas sobre Drogas). Assim sendo, por motivos que não ficam a luz da transparência ou que justifique tal decisão em documentos ou qualquer tipo de comunicação escrita, a Secretaria da Mulher da cidade fica responsável pela condução e desenvolvimento deste projeto (Integrando Famílias) dentro do município de Barueri, onde a organização social que executava as ações fica, numa estrutura formal, submetida e fiscalizada pela referida Secretaria.

\section{Descrição da O.S. "Inovação Social”}

A organização social Inovação Social foi fundada em 30/03/2012 no município de Barueri, com sua atividade principal na denominação de "atividades de associações de defesa de direitos sociais" e como finalidades secundárias como "Atividades de organizações associativas ligadas à cultura e à arte," "Atividades associativas não especificadas anteriormente" e "Outras atividades de ensino não especificadas anteriormente". Ela não mostrou trabalhos relevantes ou atuação na área social referenciada em seu ano de criação. No ano seguinte, em 2013, participou de um chamamento público realizado pela Secretaria de Suprimentos no município no primeiro semestre do ano e, como única participante deste certame, conseguiu administrar o projeto "Integrando Famílias", uma proposta de trabalho que enfoca diversos eixos, de acordo com algumas particularidades dos próprios públicos encontrados nos bairros em que foram desenvolvidas as ações, como será descrito nas figuras a seguir: 


\section{Figura 1}

\begin{tabular}{|c|c|c|}
\hline \multicolumn{3}{|c|}{$\begin{array}{l}\text { QUADRO RESUMO DE ATIVIDADES CENT } \\
\text { JARDIM PARAÍSO - SEMESTRAL - } 2013\end{array}$} \\
\hline EIXO & OFICINA & ATIVIDADE \\
\hline \multirow{7}{*}{ 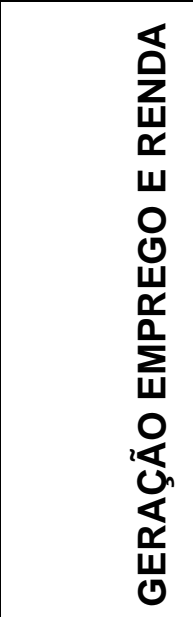 } & Artesanato & Eva, patch aplique e biscuit. \\
\hline & Empreendedorismo & Empreendedorismo \\
\hline & Gerenciamento do Lar & Area de Serviço, Cozinha e Closet \\
\hline & Esteticista & Design de sobrancelha e auto maquiagem \\
\hline & Manicure e Pedicure & Manicure e pedicure. \\
\hline & Cozinha Experimental & Doces Natalinos. \\
\hline & Confecção de Pizzas & Pizzas. \\
\hline
\end{tabular}

\section{Figura 2}

\begin{tabular}{|c|c|c|}
\hline \multicolumn{3}{|c|}{ QUADRO RESUMO DE ATIVIDADES CENTRO COMUNITÁRIO GABRIELA DE FREITAS - JARDIM } \\
\hline \multicolumn{3}{|c|}{ PARAÍSO - SEMESTRAL - 2013} \\
\hline EIXO & OFICINA & ATIVIDADE \\
\hline \multirow{9}{*}{ 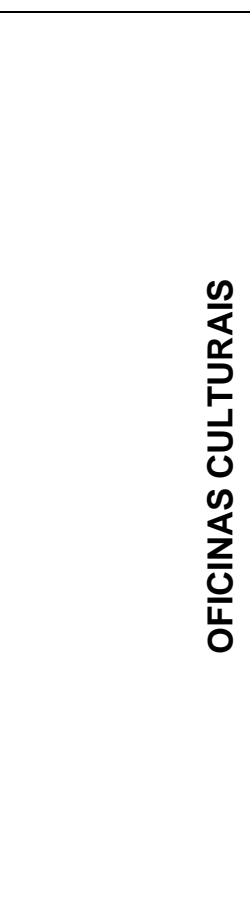 } & Artes Circenses & $\begin{array}{l}\text { Malabares, fita, perna de pau e mini } \\
\text { tramp. }\end{array}$ \\
\hline & Artes Cênicas & $\begin{array}{l}\text { Introdução a oficina de } \text { Artes } \\
\text { Cênicas }\end{array}$ \\
\hline & Artes Plástica & Projeto galeria de personagens. \\
\hline & Hip Hop & Musicalidade e coreografia. \\
\hline & Dj & $\begin{array}{l}\text { Equalização, mixagem com vinil e } \\
\text { ligação de equipamentos. }\end{array}$ \\
\hline & Grafite & Técnica de desenho. \\
\hline & Canto e Coral & $\begin{array}{l}\text { Musicalidade, técnica vocal, } \\
\text { intensidade e timbre. }\end{array}$ \\
\hline & Sopro & Notas musicais e percepção rítmica. \\
\hline & Capoeira & $\begin{array}{l}\text { Técnicas de golpes e roda de } \\
\text { capoeira. }\end{array}$ \\
\hline
\end{tabular}


Figura 3

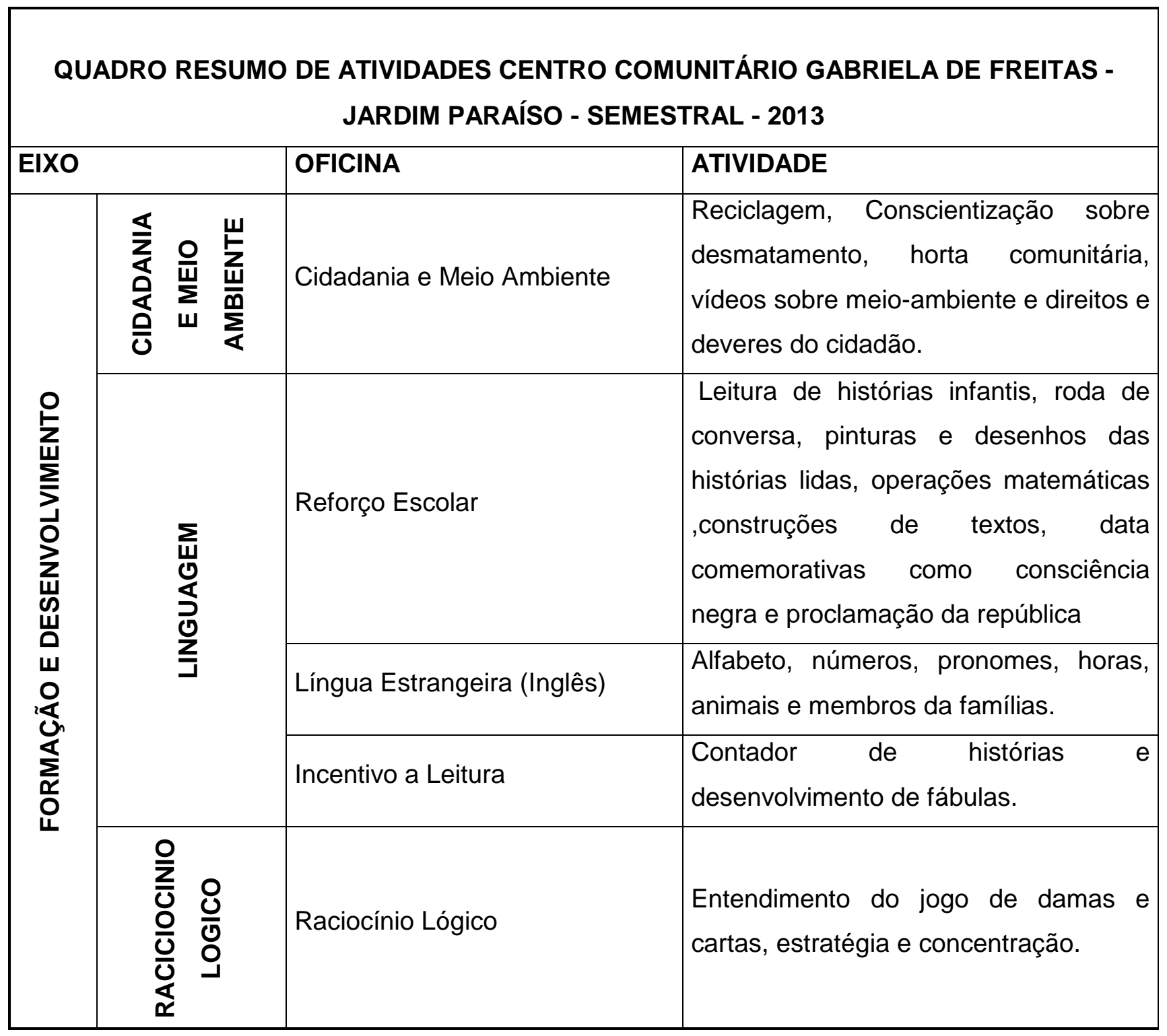

Estas informações abarcam o todo do projeto cadastrado na Prefeitura Municipal de Barueri. As atividades quase não se alteravam ou pouco eram modificadas, de acordo com o polo e bairro que ocorriam. No caso das figuras acima foi utilizado como exemplo o bairro do Jardim Paraíso por constar exatamente descrito esse polo no material de referência pesquisado.

Uma informação relevante é que o local onde as atividades eram executadas são todos da Prefeitura Municipal de Barueri e por haver um contrato de gestão é que a organização social tem permissão de utilizá-los - todos os 5 locais são prédios 
construídos pelo poder público municipal na gestão anterior ao período de 2013 e encontravam-se em utilização até o referido momento.

Um dos pontos fundamentais para execução do projeto era 0 alto índice de vulnerabilidade social, que se mostrava uma situação sine qua non para sua execução e um dos motivos que ensejaram seu surgimento - 0 alto índice de falta de atividades e tempo livre da população nos bairros periféricos. Inicialmente estavam previstos 5 centros comunitários, a saber:

\section{Figura 4}

\begin{tabular}{|c|c|c|c|}
\hline & $\begin{array}{c}\text { CENTRO } \\
\text { COMUNITÁRIO }\end{array}$ & ENDEREÇO & $\begin{array}{c}\text { ÁREA DE ABRANGÊNCIA } \\
\text { (BAIRROS) }\end{array}$ \\
\hline 1 & Jaraguá Mirim & $\begin{array}{l}\text { Rua Otacílio Alves Martins, } n \text {. } \\
514 \text { - Parque Imperial }\end{array}$ & $\begin{array}{l}\text { Parque Imperial e Jardim } \\
\text { Mutinga }\end{array}$ \\
\hline 2 & $\begin{array}{l}\text { Hercília da Silva } \\
\text { Barbosa }\end{array}$ & $\begin{array}{l}\text { Rua Hercília da Silva Barbosa, } \\
\text { n. } 101 \text { - Parque Imperial }\end{array}$ & $\begin{array}{llll}\text { Parque Imperial e Jardim } \\
\text { Mutinga }\end{array}$ \\
\hline 3 & $\begin{array}{l}\text { João Ricardo } \\
\text { Pelúcio }\end{array}$ & $\begin{array}{l}\text { Rua Otávio Calegari, n. } 66- \\
\text { Engenho Novo }\end{array}$ & $\begin{array}{ll}\text { Engenho } & \text { Novo, Cruz Preta, } \\
\text { Jardim } & \text { Califórnia, São } \\
\text { Silvestre e Jardim Flórida }\end{array}$ \\
\hline 4 & $\begin{array}{l}\text { Gabriela } \\
\text { Freitas }\end{array}$ & $\begin{array}{l}\text { Rua Tayo, n.310 - Jardim } \\
\text { Paraíso }\end{array}$ & $\begin{array}{l}\text { Jardim Paraíso, Vila } \\
\text { Morelato, Jardim Tupancy e } \\
\text { Jardim Reginalice }\end{array}$ \\
\hline 5 & $\begin{array}{l}\text { Parque } \\
\text { Camargos }\end{array}$ & $\begin{array}{l}\text { Rua Irene, n. } 534 \text { - Parque dos } \\
\text { Camargo }\end{array}$ & $\begin{array}{l}\text { Jardim Tupã, Vale do Sol, } \\
\text { Jardim Silveira e Jardim } \\
\text { Paulista }\end{array}$ \\
\hline
\end{tabular}

Fonte: Projeto Gestão dos Centros Comunitários para Crianças, Adolescentes e Famílias, 2013

O orçamento inicialmente previsto contemplava as 5 unidades descritas. Por um critério de organização, efetivamente 4 centros comunitários foram idealizados: Paraíso, Engenho Novo, Mutinga e Parque dos Camargos. O projeto iniciou no dia 01/08/2013 e perdurou até a data de 30/05/2014, onde suas atividades foram encerradas. Neste período, na fase de início das atividades, cerca de 100 funcionários 
iniciaram as atividades com a organização e, ao finalizar as atividades, haviam exatamente 128 funcionários na folha de pagamento (Relação de Funcionários, 2014). De acordo com o Tribunal de Contas do Estado de São Paulo, em seus doze meses de funcionamento os repasses que foram realizados somam o montante de $R \$$ 11.114.929,29, conforme tabela abaixo:

\section{Tabela 1}

\begin{tabular}{|c|c|c|c|l|}
\hline EMPENHO & CNPJ & FORNECEDOR & $\begin{array}{c}\text { DIA DO } \\
\text { PAGAMENTO }\end{array}$ & VALOR (R\$) \\
\hline $13274-2013$ & 15336047000106 & ASSOCIACAO INOVACAO SOCIAL & $27 / 06 / 2013$ & $1.111 .492,93$ \\
\hline $13274-2014$ & 15336047000106 & ASSOCIACAO INOVACAO SOCIAL & $26 / 07 / 2013$ & $1.111 .492,93$ \\
\hline $13274-2015$ & 15336047000106 & ASSOCIACAO INOVACAO SOCIAL & $06 / 09 / 2013$ & $1.111 .492,93$ \\
\hline $13274-2016$ & 15336047000106 & ASSOCIACAO INOVACAO SOCIAL & $26 / 09 / 2013$ & $1.111 .492,93$ \\
\hline $13274-2017$ & 15336047000106 & ASSOCIACAO INOVACAO SOCIAL & $13 / 11 / 2013$ & $444.597,19$ \\
\hline $13274-2018$ & 15336047000106 & ASSOCIACAO INOVACAO SOCIAL & $04 / 12 / 2013$ & $889.194,34$ \\
\hline $13274-2019$ & 15336047000106 & ASSOCIACAO INOVACAO SOCIAL & $13 / 12 / 2013$ & $889.194,34$ \\
\hline $1553-2014$ & 15336047000106 & ASSOCIACAO INOVACAO SOCIAL & $16 / 01 / 2014$ & $889.194,34$ \\
\hline $3129-2014$ & 15336047000106 & ASSOCIACAO INOVACAO SOCIAL & $21 / 02 / 2014$ & $889.194,34$ \\
\hline $6331-2014$ & 15336047000106 & ASSOCIACAO INOVACAO SOCIAL & $27 / 03 / 2014$ & $889.194,34$ \\
\hline $7218-2014$ & 15336047000106 & ASSOCIACAO INOVACAO SOCIAL & $08 / 04 / 2014$ & $889.194,34$ \\
\hline $8911-2014$ & 15336047000106 & ASSOCIACAO INOVACAO SOCIAL & $05 / 05 / 2014$ & $889.194,34$ \\
\hline & & & $11.114 .929,29$ \\
\hline
\end{tabular}

Fonte: $\quad$ http://www.portaldocidadao.tce.sp.gov.br/despesas id/13/33/2013/despesas (acessado em $20 / 08 / 2015$ às 17:01)

http://www.portaldocidadao.tce.sp.gov.br/despesas id/13/33/2014/despesas (acessado em 20/08/2015 às 18:15)

Em uma base comparativa, outras associações ou organizações sociais que prestam serviço na área de promoção social (infância/juventude e grupo de idosos) do município de Barueri receberam os seguintes valores no mesmo período-base: 


\section{Tabela 2}

\begin{tabular}{|c|c|c|}
\hline \multicolumn{3}{|l|}{ REPASSE DA PREFEITURA ȦS ENTIDADES SOCIAIS EM 2014} \\
\hline ENTIDADE SOCIAL & T.C. № & VALOR \\
\hline ACM - ASSOCIAÇÃO CRISTÃ DE MOÇOS DE SÃO PAULO & $01 / 14$ & $\mathrm{R} \$ 217.728,00$ \\
\hline ASSOCIAÇÃO ASSISTENCIAL PARÓQUIA SÃO JOÃO BATISTA DE BARUERI & $02 / 14$ & $\mathrm{R} \$ 225.000,00$ \\
\hline ASSOCIAÇÃO CULTURAL E EDUCACIONAL FUTURO MELHOR & $03 / 14$ & $\mathrm{R} \$ 282.625,20$ \\
\hline ASSOCIAÇÃO DA VILA ILHÉUS & $04 / 14$ & $\mathrm{R} \$ 440.725,30$ \\
\hline ASSOCIAÇÃO VIVA FELIZ & $05 / 14$ & $\mathrm{R} \$ 307.809,23$ \\
\hline CAMP & $06 / 14$ & $\mathrm{R} \$ 546.249,36$ \\
\hline CEPAC & $07 / 14$ & $\mathrm{R} \$ 376.177,72$ \\
\hline CEPAC & $08 / 14$ & $\mathrm{R} \$ 154.274,89$ \\
\hline CEPAC & $09 / 14$ & $\mathrm{R} \$ 1.014 .561,48$ \\
\hline CEPAC & $10 / 14$ & $R \$ 21.600,00$ \\
\hline ORGANIZAÇÃO FÊNIX & $11 / 14$ & $\mathrm{R} \$ 301.001,26$ \\
\hline GRUPO VIDA BRASIL & $12 / 14$ & $\mathrm{R} \$ 3.017 .409,78$ \\
\hline GRUPO VIDA BRASIL & $13 / 14$ & $\mathrm{R} \$ 387.055,08$ \\
\hline GRUPO VIDA BRASIL & $14 / 14$ & $\mathrm{R} \$ 2.031 .055,08$ \\
\hline INSTITUTO BARUERI PARAOLÍMPICO & $15 / 14$ & $R \$ 203.672,00$ \\
\hline IEPPC - INSTITUTO SOCIAL PARQUE DOS CAMARGOS & $16 / 14$ & $R \$ 309.368,64$ \\
\hline PROJAB - PROJETO DE AÇÃO SOCIAL DE BARUERI & $17 / 14$ & $\mathrm{R} \$ 420.558,92$ \\
\hline ASSOCIAÇÃO PROJOV - PROGRAMA ROTÁRIO PARA JOVENS & $18 / 14$ & $\mathrm{R} \$ 127.080,00$ \\
\hline ASSOCIAÇÃO PROJOV - PROGRAMA ROTÁRIO PARA JOVENS & $19 / 14$ & $\mathrm{R} \$ 14.734,80$ \\
\hline SAF - ASSOCIAÇÃO DE APOIO À FAMÍLIA & $20 / 14$ & $\mathrm{R} \$ 258.671,34$ \\
\hline SAF - ASSOCIAÇÃO DE APOIO Ȧ FAMÍLIA & $21 / 14$ & $\mathrm{R} \$ 194.554,79$ \\
\hline INSTITUTO DE INTEGRAÇÃO SOCIAL DE BARUERI - INSB & $23 / 14$ & $\mathrm{R} \$ 399.550,01$ \\
\hline INSTITUTO DE INTEGRAÇÃO SOCIAL DE BARUERI - INSB & $24 / 14$ & $\mathrm{R} \$ 383.652,84$ \\
\hline ASSOCIAÇÃO AMIGOS DE BARUERI E REGIÃO - AABR & $25 / 14$ & $\mathrm{R} \$ 297.254,74$ \\
\hline ASSOCIAÇÃO PROFISSIONALIZANTE E AÇÃO SOCIAL - ASSPAS & $30 / 14$ & $\mathrm{R} \$ 267.096,70$ \\
\hline GRUPO DE APOIO DE INTEGRAÇÃO SOCIAL DE BARUERI - GAISB & $33 / 14$ & $\mathrm{R} \$ 286.590,40$ \\
\hline ASSOCIAÇÃO CULTURAL PROMOART & $34 / 14$ & $\mathrm{R} \$ 404.904,59$ \\
\hline ASSOCIAÇÃO AMIGOS DE BARUERI E REGIÃO - AABR & $35 / 14$ & $\mathrm{R} \$ 397.254,74$ \\
\hline ASSOCIAÇÃO PROJOV - PROGRAMA ROTÁRIO PARA JOVENS & $48 / 14$ & $\mathrm{R} \$ 135.265,20$ \\
\hline GRUPO VIDA BRASIL & $49 / 14$ & $\mathrm{R} \$ 7.440,00$ \\
\hline GRUPO VIDA BRASIL & $50 / 14$ & $\mathrm{R} \$ 9.360,00$ \\
\hline CEPAC & $51 / 14$ & $\mathrm{R} \$ 180.265,20$ \\
\hline ASSOCIAÇÃO ASSISTENCIAL PARÓQUIA SÃO JOÃO BATISTA DE BARUERI & $52 / 14$ & $\mathrm{R} \$ 135.265,20$ \\
\hline ACM - ASSOCIAÇÃO CRISTÃ DE MOÇOS DE SÃO PAULO (CMDCA) & $53 / 14$ & $\mathrm{R} \$ 10.000,00$ \\
\hline APAE & $54 / 14$ & $\mathrm{R} \$ 22.400,00$ \\
\hline CEPAC & $55 / 14$ & $\mathrm{R} \$ 62.400,00$ \\
\hline
\end{tabular}




\begin{tabular}{|l|l|l|} 
CEPAC & $56 / 14$ & $\mathrm{R} \$ 36.000,00$ \\
\hline CEPAC & $57 / 14$ & $\mathrm{R} \$ 84.000,00$ \\
\hline ASSOCIAÇÃO CULTURAL E EDUCACIONAL FUTURO MELHOR & $58 / 14$ & $\mathrm{R} \$ 4.000,00$ \\
\hline PROJOV - PROGRAMA ROTÁRIO PARA JOVENS & $59 / 14$ & $\mathrm{R} \$ 800,00$ \\
\hline CAMP & $70 / 14$ & $\mathrm{R} \$ 40.000,00$ \\
\hline BARUERI AMPARO E UNIÃO SOCIAL & $71 / 14$ & $\mathrm{R} \$ 146.863,15$ \\
\hline
\end{tabular}

Fonte: Diário Oficial do Município de Barueri

Sendo assim, instituições que já atuam há muito mais tempo, algumas das quais com mais de duas décadas de atuação - como no caso da ONG Grupo Vida Barueri no município e também em áreas com risco e vulnerabilidade sociais receberam, em um ano, o equivalente no ano de 2014 em comparação com a organização social supracitada:

\section{Tabela 3}

\begin{tabular}{|c|c|c|}
\hline \multicolumn{3}{|c|}{$\begin{array}{l}\text { BASE COMPARATIVA DE REPASSE DE RECURSOS EM } 2014 \text { - O.S. INOVAÇÃO } \\
\text { SOCIAL }\end{array}$} \\
\hline ENTIDADE SOCIAL & TOTAL (R\$) & $\%$ \\
\hline ACM - ASSOCIAÇÃO CRISTÃ DE MOÇOS DE SÃO PAULO & $227.728,00$ & $2,05 \%$ \\
\hline APAE & $22.400,00$ & $0,20 \%$ \\
\hline ASSOCIAÇÃO AMIGOS DE BARUERI E REGIÃO - AABR & $694.509,48$ & $6,25 \%$ \\
\hline $\begin{array}{l}\text { ASSOCIAÇÃO ASSISTENCIAL PARÓQUIA SÃO JOÃO } \\
\text { BATISTA DE BARUERI }\end{array}$ & $360.265,20$ & $3,24 \%$ \\
\hline $\begin{array}{l}\text { ASSOCIAÇÃO } \\
\text { MELULTURAL E }\end{array}$ & 286.625,20 & $2,58 \%$ \\
\hline ASSOCIAÇÃO CULTURAL PROMOART & $404.904,59$ & $3,64 \%$ \\
\hline ASSOCIAÇÃO DA VILA ILHÉUS & $440.725,30$ & $3,97 \%$ \\
\hline $\begin{array}{l}\text { ASSOCIAÇÃO PROFISSIONALIZANTE E AÇÃO SOCIAL - } \\
\text { ASSPAS }\end{array}$ & $267.096,70$ & $2,40 \%$ \\
\hline $\begin{array}{l}\text { ASSOCIAÇÃO PROJOV - PROGRAMA ROTÁRIO PARA } \\
\text { JOVENS }\end{array}$ & $277.080,00$ & $2,49 \%$ \\
\hline ASSOCIAÇÃO VIVA FELIZ & $307.809,23$ & $2,77 \%$ \\
\hline BARUERI AMPARO E UNIÃO SOCIAL & $146.863,15$ & $1,32 \%$ \\
\hline
\end{tabular}




\begin{tabular}{|l|c|c|} 
CAMP & $586.249,36$ & $5,27 \%$ \\
\hline CEPAC & $1.929 .279,29$ & $17,36 \%$ \\
\hline GRUPO DE APOIO DE INTEGRAÇÃO SOCIAL DE BARUERI & & \\
- GAISB & $286.590,40$ & $2,58 \%$ \\
\hline GRUPO VIDA BRASIL & $5.452 .319,94$ & $49,05 \%$ \\
\hline IEPPC - INSTITUTO SOCIAL PARQUE DOS CAMARGOS & $309.368,64$ & $2,78 \%$ \\
\hline INSTITUTO BARUERI PARAOLÍMPICO & $203.672,00$ & $1,83 \%$ \\
\hline INSTITUTO DE INTEGRAÇÃO SOCIAL DE BARUERI - INSB & $783.202,85$ & $7,05 \%$ \\
\hline ORGANIZAÇÃO FÊNIX & $301.001,26$ & $2,71 \%$ \\
\hline PROJAB - PROJETO DE AÇÃO SOCIAL DE BARUERI & $420.558,92$ & $3,78 \%$ \\
\hline PROJOV - PROGRAMA ROTÁRIO PARA JOVENS & 800,00 & $0,01 \%$ \\
\hline SAF - ASSOCIAÇÃO DE APOIO À FAMÍLIA & $453.226,13$ & $4,08 \%$ \\
\hline
\end{tabular}

Fonte: Elaborado pelo autor.

Analisando-se os dados é permitido aferir o caráter de importância que foi atribuído à O.S. Inovação Social - neste caso, pela alocação de recursos no curto espaço de tempo com relação a outras organizações que já vigoravam na cidade - e o seu projeto no município, pois a abrangência, escopo e alocação financeira foi a maior destinada a uma organização do terceiro setor na história e nos registros do município.

Dado este cenário, três hipóteses são elencadas para justificar a não distribuição dos mesmos recursos financeiros entre as 27 instituições de terceiro setor com registro no CMAS (Conselho Municipal de Assistência Social) ou nas 23 instituições com registro no CMDCA (Conselho Municipal dos Direitos da Criança e do Adolescente de Barueri) - algumas instituições compartilham dos dois cadastros, outras não - existentes na cidade ou pela não contratação de funcionários públicos (através de concurso público) para executar esse projeto:

1. A facilidade de contratação de pessoal e dispensa destes, caso os funcionários não agissem de acordo com a proposta inicial aprovada;

2. Ter facilidade na modificação das ações e ter uma maior abrangência demográfica, pois as outras organizações - apesar de já atuarem em alguns bairros do 
qual a Inovação Social atuava - têm sua própria autonomia e espaço de realização e, uma vez estabelecidos e aprovados anteriormente, seriam de difícil modificação. No caso dos centros comunitários, com uma melhor estrutura física (cedida pela Prefeitura) e com maior facilidade na resolução das contingências que houvessem, a O.S. estaria mais apta, pois estava vinculada a uma Secretaria Municipal que não cuidava dos assuntos do terceiro setor (Promoção Social), e sim a uma outra Secretaria: da Mulher;

3. Facilidade de "acomodação política" (verificar o item 4 e 5 a seguir)

\section{Análise da execução do projeto}

O projeto surgiu da necessidade de aproveitamento de alguns próprios públicos que foram entregues durante os anos de 2009, 2010 e 2011. Esses eram grandes estruturas localizadas no centro dos bairros periféricos, com milhares de metros quadrados construídos. Logo que iam sendo disponibilizados à população, cada um em seu devido bairro, o projeto "Bairro Escola", que era implementado nas unidades tentava suprir a lacuna de lazer e entretenimento para os jovens e as famílias. Este projeto foi desenvolvido pela Secretaria de Ações Sociais e Cidadania (atual Secretaria de Promoção Social). Na troca de gestão, a partir do ano de 2013, os centros comunitários continuaram suas atividades, através da Secretaria de Promoção Social.

Houve um chamamento público para a seleção de organizações sociais interessadas em operacionalizar as atividades nos centros comunitários logo nos primeiros meses de 2013. Tendo em vista a magnitude de processo, houveram alguns questionamentos por parte da Secretaria de Negócios Jurídicos do município, tanto no momento da criação das exigências e obrigações da contratada quanto na prestação de contas deste Contrato de Gestão. Assim que a organização social Inovação Social conseguiu as atribuições necessárias no município e se qualificou, vencendo, o chamamento público, em seu escopo as atribuições agora eram pertencentes à Secretaria da Mulher. 
As atividades dos centros comunitários começaram, efetivamente no mês de setembro de 2013. Na primeira etapa de contratação, de acordo com relatos dos profissionais que atuavam diretamente na O.S., aproximadamente 100 funcionários foram contratados para iniciarem o planejamento, a prestação de contas, as oficinas, os programas e os cursos. Desses profissionais, todos, sem exceção, foram através do formato "quem indicou" ou por critério político (normalmente um pedido de vereador). $\mathrm{O}$ restante, 28 profissionais, foram recrutados no mercado de trabalho, por análise curricular e de forma meritocrática.

Em um primeiro momento, as atividades culturais eram as mais procuradas pelos jovens e famílias da comunidade, em especial as de ballet, circo, street dance e grafite. Em seguida vinham as atividades esportivas, como os esportes de quadra (vôlei e futebol de salão) e artes marciais (capoeira, judô e karatê). Por último vinham as atividades de geração de renda, como design de sobrancelhas, maquiagem, unhas, gerenciamento do lar e confeitaria.

As ações, por estarem voltados às crianças e aos adolescentes, utilizavam o contraturno escolar para ter público e preencher o período considerado "vago" após as aulas - pela manhã e pela tarde. Bem no princípio, os usuários dos serviços iam por seus próprios meios (normalmente a pé) para as atividades. Com poucas semanas de atividade, os centros comunitários começaram a dispor de ônibus para ir para os bairros mais afastados e ter acesso a outro público, aqueles de bairros mais afastados da comunidade, dos quais os munícipes reclamavam de não haver essas estruturas públicas mais próximas de suas residências.

A unidade do centro comunitário do Jaraguá Mirim, que estava inicialmente previsto no cronograma financeiro oficial, foi descontinuada por uma questão de planejamento-operacional. Assim, no 5ำ mês de pagamento a O.S., o valor de repasse do contrato de gestão teve um decréscimo de $60 \%$ (reduziu o equivalente de $R \$$ $666.895,74)$ que seriam referentes aos 4 meses de atividade deste centro comunitário que não foram realizadas.

De maneira geral, a comunidade do entorno das unidades participavam e se envolviam nas atividades, sejam através das crianças/jovens ou mesmo os pais dessas crianças, que não trabalhavam ou eram "do lar". 


\section{Análise da descontinuidade do projeto}

O projeto, apesar de ter uma boa aceitação de público e ter uma alta destinação de recursos financeiros, foi descontinuado por diversos motivos. Pode-se começar a análise pelo próprio critério financeiro: a dificuldade de prestação de contas dos recursos destinados. Diversas incongruências nos relatórios financeiros eram incompatíveis com a realidade do projeto naquele período analisado. Esses relatórios eram, via de regra, apresentados à Secretaria da Mulher (apresentação dos resultados/ações) e para a Secretaria de Suprimentos (apresentação dos dados econômicos/financeiros). Uma informação aferida que corrobora esse fato é que as contas do mês de outubro de 2013, até o mês de fevereiro de 2014 não haviam sido justificadas na maneira legal que a Secretaria de Suprimentos solicitava. Erros caracterizados como crassos foram observados nestes documentos (relatórios) por esta última Secretaria, como incompatibilidade de valores, o não seguimento do procedimento de compras adequado e a não realização de serviços ou entrega de materiais que eram adquiridos. Isso foi diminuindo a credibilidade do projeto, pois a mesma Secretaria de Suprimentos necessitava justificar os valores repassados para o Tribunal de Contas do Estado de São Paulo - os repasses dos contratos de gestão - e isso causava um "efeito dominó" nas prestações de contas dos contratos municipais.

Outro fator que se mostrou complicador da situação foi a "indicação" por agentes políticos de pessoas para trabalharem diretamente dentro da O.S. Muitas das pessoas indicadas e que lá trabalhavam não possuíam habilidade técnica ou experiência legitimada para orientar ou conduzir os trabalhos realizados. Um caso que comprova isso é a presidente (cargo voluntário) da O.S. ser sobrinha da antiga Secretária da Mulher. Dentro deste contexto, outros casos também foram verificados: a gerente financeira do projeto (cargo remunerado) era sobrinha da mesma Secretária. A gestora administrativa do projeto (cargo remunerado) era tia da presidente da O.S. A coordenadora de conservação (cargo remunerado) era a tia da presidente da O.S. Uma das assistentes administrativas que trabalhavam na sede do projeto era prima da presidente da O.S. Um dos monitores (cargo remunerado) também era parente da presidente. Um dos agentes comunitários (cargo remunerado) era tia da presidente da O.S. Haviam, também, indicações de pessoas que atuavam e foram conseguidas através de pedidos ou solicitações de vereadores do município diretamente ao gestor 
do projeto. Isso fez com que muitas pessoas consideradas "indicadas" ou "protegidas" conseguissem emprego e atuassem diretamente nos centros comunitários. Não há ao certo a quantidade de pessoas que adentraram desta forma (indicação) no projeto, entretanto é possível de se afirmar que elas adentraram no primeiro momento de contratação (entre os 100 primeiros funcionários contratados). Desta forma, evidenciase uma espécie de "cabide" ou indicações diretas de emprego para facilitação de algumas funções ou resolução de situações políticas locais.

Em março de 2014 houve a ruptura do ciclo de atendimento à comunidade local em todos os bairros. Foi anunciada, em reunião com todos os funcionários em uma das unidades que teria de demitir 120 funcionários naquele dia. Em discurso feito pela presidente da O.S., os motivos alegados foram que houvera a rescisão por parte da Secretaria da Mulher, sem maiores explicações ou detalhamentos dos motivos. $\mathrm{Na}$ visão de pessoas que estavam presentes, o discurso que prevalecia era que a má administração até o instante tinha culminado com esse processo.

Após a rescisão, para que não se cessassem por completo as atividades, a Secretaria de Cultura do município encaminhou profissionais do campo das Artes (teatro, ballet e violão) para dar prosseguimento aos programas no contraturno escolar. Uma empresa prestadora de serviços nos centros comunitários, em um acordo com o poder público, contratou professores de Hip Hop, Rap e Percussão para continuidade do trabalho que estava suspenso.

A comunidade local, mesmo com a saída da O.S. Inovação Social, não foi renegada e deixada sem atividades - o município providenciou a continuidade através das Secretarias Municipais (Cultura e Mulher). Neste período, as atividades ficaram suspensas em todos os centros comunitários por uma semana. A Secretaria que conduziu o processo de transição foi a Secretaria da Mulher.

\section{Considerações Finais}

As organizações sociais se constituem de maneira formal e tradicional às fundações e associações sem fins lucrativos, mas representam uma "inovação institucional" (Modesto, 1997) por estabelecer um novo relacionamento entre o Estado e as instituições que possuem relevância social. Desta forma, abre um espaço a novos meios de captação de recursos, realização dos programas e gestão das organizações, tendo em vista a construção ou recuperação da cidadania de grupos em situação de 
risco, mais especificamente as crianças e jovens de classes desfavorecidas (Silva e Dellagnelo, 2004).

A experiência analisada em Barueri, no que tange à utilização de Organizações Sociais para a gestão de centros comunitários, extrapolou o uso costumeiro desse modelo na área da saúde e demonstrou que a ferramenta organizacionaladministrativa tem potencial e consegue suprir uma lacuna na gestão pública municipal, em especial em áreas de difícil acesso e com risco social aderente. Através de um mecanismo legal-burocrático (leia-se chamamento público) consegue-se ter uma participação de entidades que atuem no terceiro setor para, concomitantemente com o poder público, atuarem nos espaços geográficos com maiores desafios sociais. Entretanto, um dos critérios mais difíceis de mensurar neste campo é a avaliação do impacto e dos resultados dos projetos sociais, pois geralmente estes são um requisito para a obtenção de recursos por parte das agências financiadoras. De acordo Cabral (2011) as agências financiadores monitoram a efetividade dos resultados alcançados ou a eficiência de sua relação custo-benefício, doravante o que se encontra no terceiro setor é uma incipiente profissionalização dos recursos humanos do setor e a falta de uma cultura sistemática e difundida no campo social que consiga expressar o conteúdo real e valorativo das ações sociais.

A operacionalização do trabalho executado de acordo com o programa estabelecido mostrou-se eficaz - o que demonstra isso são os indícios de aceitação e colaboração da comunidade local no cotidiano das ações. Em contraposição, a gerência dos recursos humanos configurou-se como um desafio a parte, pois os funcionários, muitas das vezes, não agiam de acordo com o esperado ou criavam-se dificuldades políticas em uma possível demissão. Isto evidenciou o nível de interferência política, tanto para admissão de funcionários quanto para sua possível demissão. Por essa razão, se fragilizou ou se comprometeu algumas frentes do projeto e se tornou, não obstante, um dos motivos de maior fragilidade na execução das ações. Há indícios de corporativismo político, onde vereadores protegem ou "seguram" indicações políticas para seus apoiadores ou pessoas de confiança dentro deste projeto. Bresser-Pereira (2010) explica que o patrimonialismo é a incapacidade de o governante não diferenciar os bens privados do patrimônio público, ou seja, de se apropriar dos bens públicos para a utilização de objetivos privados ou de um grupo específico. Nesse sentido, evidenciam-se aspectos institucionalizados na cultura do 
projeto, que permaneceram como uma ferramenta de "acomodação política" ou "moeda de troca" para transações políticas.

Por outro lado, a descontinuidade do projeto culminou para que outra organização social desse prosseguimento ao "passivo social", assumindo o locus deixado anteriormente pela O.S. Inovação Social e melhorasse sua proposta inicialmente implementada. Assim, os centros comunitários continuam até o presente momento com execução de atividades e em atendimento contínuo aos bairros.

Por ser um tema recente nos estudos organizacionais, ainda não existem modelos teóricos para uma análise mais aprofundada e que suscitem maiores relações com racionalidades organizacionais já estruturadas. Essa pode ser considerada uma limitação desse estudo. Todavia, as organizações deste nível estão inseridas em ambientes próprios, onde um projeto social, via de regra, tenta resgatar a relação homem-sociedade e inserir em seu bojo os princípios de cidadania e interação entre as pessoas, por isso as contingências advindas nestas realidades estão intrinsicamente relacionadas ao conflito dos valores estabelecidos versus os valores que estão sendo concebidos no decorrer do processo.

Essa pesquisa se concentrou em estudar a relação de distribuição de recursos municipais, tanto os financeiros como os humanos, do projeto desta organização social, remontando a comparação com outros projetos em vigor e também do mérito inovativo na utilização desta ferramenta na gestão municipal. Traz, também, como evidência empírica um apontamento importante na constatação de que "uma maior quantidade de recurso (financeiro/humano)" não necessariamente se traduz em "maior eficiência/longevidade" ao longo da prestação de serviços.

Recomenda-se, portanto, que novos estudos sejam conduzidos para se fundamentar os aspectos da gestão das organizações sociais, seus processos decisórios, a relação com o poder (local e do Estado), as configurações culturais, sociais e simbólicas que caracterizam essas entidades de interesse social. 


\section{Referências Bibliográficas}

ALMEIDA, Vinícius Silveira de. Formas de cooperação, negociação e conflito no setor público: a análise estratégica da Secretaria de Planejamento, Gestão, Transportes e Suprimentos de Barueri de acordo com Michel Crozier. Saarbrücken, Deutschland: Novas Edições Acadêmicas, 2015

ANDRADE, Raquel Dully; de Mello ,Débora Falleiros. Organizações sociais e instituições governamentais: perspectivas de parceria na atenção à saúde da criança através dos voluntários e da pastoral da criança. Revista da Escola de Enfermagem da USP, São Paulo, v.40, n.1, Mar. 2006

BASSOTTI, Ivani Maria; PINTO, Sandra Souza; SANTOS, Thiago Souza. Uma nova gestão é possível. São Paulo: FUNDAP - Unidade Central de Recursos Humanos da Secretaria de Planejamento e Gestão, 2015.

BERGER, P. L.; LUCKMANN, T. The social construction of reality: a treatise in the sociology of knowledge. New York: Doubleday Anchor Book, 1967

BRESSER-PEREIRA, Luiz Carlos. Democracia, Estado social e reforma gerencial. Revista de Administração de Empresas, São Paulo, v.50, n.1, jan./mar. 2010

Caracterização do Projeto - Centros Comunitários de Barueri - Divulgação própria. O.S. Inovação Social, 2013

CABRAL, Eloisa Helena de Souza. Valores e espaço público: referenciais e instrumentos para a avaliação de projetos sociais. Revista de Administração Pública, Rio de Janeiro, v.45, n.6, nov./dez. 2011

CROZIER, Michel. Fenômeno burocrático. Brasília: Editora UNB, 1981.

DIÁRIO OFICIAL DE BARUERI - Edição 464. Prefeitura Municipal de Barueri. Barueri. Disponível em: http://www.barueri.sp.gov.br/sites/scs/downloads/2014_01_04.pdf. Acesso em: 8 set. 2015. 
DIÁRIO OFICIAL DE BARUERI - Edição 466. Prefeitura Municipal de Barueri. Disponível em:

http://www.barueri.sp.gov.br/sites/scs/downloads/2014_01_09.pdf Acesso em: 8 set. 2015.

DIÁRIO OFICIAL DE BARUERI - Edição 484. Prefeitura Municipal de Barueri.

Disponível em: http://www.barueri.sp.gov.br/sites/scs/downloads/2014_02_20.pdf Acesso em: 8 set. 2015.

DIÁRIO OFICIAL DE BARUERI - Edição 491. Prefeitura Municipal de Barueri. Disponível em:

http://www.barueri.sp.gov.br/sites/scs/downloads/2014_03_13.pdf Acesso em: 8 set. 2015.

DIÁRIO OFICIAL DE BARUERI - Edição 504. Prefeitura Municipal de Barueri. Disponível em: http://www.barueri.sp.gov.br/sites/scs/downloads/2014_04_15.pdf Acesso em: 8 set. 2015.

DIÁRIO OFICIAL DE BARUERI - Edição 523. Prefeitura Municipal de Barueri. Disponível em: http://www.barueri.sp.gov.br/sites/scs/downloads/2014_06_05.pdf. Acesso em: 8 set. 2015.

DIÁRIO OFICIAL DE BARUERI - Edição 546. Prefeitura Municipal de Barueri.

Disponível em: http://www.barueri.sp.gov.br/sites/scs/downloads/2014_08_05.pdf Acesso em: 8 set. 2015.

Grade de Atividades - 4 Centros Comunitários: Parque Imperial, Jardim Paraíso, Engenho Novo e Parque dos Camargos - Divulgação própria. O.S. Inovação Social, Mai 2014

HIRONOBU, Sano; Abrucio, Fernando Luiz. Promessas e resultados da Nova Gestão Pública no Brasil: o caso das Organizações Sociais de saúde em São Paulo. Revista de Administração de Empresas, São Paulo, v.48, n.3, jul./set. 2008 
Ibañez, Nelson; Bittar, Olímpio José Nogueira Viana; Castro Sá , Evelin Naked de; Yamamoto, Edison Keiji; Almeida, Márcia Furquim de; Castro, Cláudio Gastão Junqueira de. Organizações sociais de saúde: o modelo do Estado de São Paulo. Revista Ciência \& Saúde Coletiva, Rio de Janeiro, v.6, n.2, 2001

MELO, Cristina; TANAKA, Oswaldo. As organizações sociais no setor saúde: Inovando as formas de gestão? Organizações e Sociedade, Salvador, v.8, n.22, set./dec. 2001

Mello e Silva, Sylvio Bandeira de; Silva , Barbara-Christine Nentwig; Pirajá Silva , Maina. Organização social e indicadores socioeconômicos no Brasil: um estudo exploratório. Caderno CRH, Salvador, v.22, n.57, 2009

MODESTO, Paulo Eduardo Garrido. Reforma administrativa e marco legal das organizações sociais no Brasil: as dúvidas dos juristas sobre o modelo das organizações sociais. Revista do Serviço Público - RSP, Brasília, v.48, n.2, 1997

MOREIRA NETO, Diogo de Figueiredo. Curso de Direito Administrativo 16ํㅡㄹição. Rio de Janeiro: Ed. Forense, 2014.

Projeto Gestão dos Centros Comunitários para Crianças, Adolescentes e Famílias Centros Comunitários de Barueri- Divulgação própria. O.S. Inovação Social, 2013

Relatório Semestral - Projeto Integrando Famílias - Divulgação própria. O.S. Inovação Social, jul./dez. 2013.

Relatório Quimestral - Projeto Integrando Famílias - Divulgação própria. O.S. Inovação Social, jan./mai. 2014.

Relação de Funcionários - Divulgação própria. O.S. Inovação Social, Mai 2014. 
SCHMIDT, Vera Viviane. Coerência programática e disciplina parlamentar: partidos políticos frente à proposta das organizações sociais. Revista de Sociologia e Política, Curitiba, v.19, n.40, Oct. 2011

SILVA; Rosimeri Carvalho da; DELLAGNELO, Eloise Livramento. Redes de organizações sociais: a inserção da lógica de mercado e a formação de gestores. Caderno EBAPE.BR, Rio de Janeiro, v.2, n.3, Dec. 2004

SANTOS, Leane Mota Araujo dos; LOPES, Fernando Dias; Añez, Miguel Eduardo Moreno. Análise crítica em organizações sociais: apropriando teoria e prática de seus componentes estruturais e culturais. Caderno EBAPE.BR, Rio de Janeiro, v.5, n.2, Jun. 2007

SANTOS, Sandra Maria Chaves dos; GUIMARÃES, Maria do Carmo Lessa; MELO, Cristina Maria Meira de; FILHO, Alvino Sanches. Subsídios para avaliação da gestão pública: processo de construção de indicadores para avaliação da capacidade de gestão de organizações sociais. Organizações e Sociedade, Salvador, v.13, n.37, abr./jun. 2006

1998b. Lei 9 637, de 15 de maio. Dispõe sobre a qualificação de entidades como organizações sociais, a criação do Programa Nacional de Publicização, a extinção dos órgãos e entidades que menciona e a absorção de suas atividades por organizações sociais, e dá outras providências. Diário Oficial. Brasília, 15.mai.1998. Disponível em: http://www.planalto.gov.br/CCivil_03/Leis/L9637.htm Acesso em: 01.jul.2015. 